\title{
Contrasting response of hydrological cycle over land and ocean to a changing $\mathrm{CO}_{2}$ pathway
}

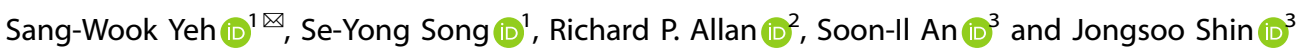

The hydrological cycle has a significant impact on human activities and ecosystems, so understanding its mechanisms with respect to a changing climate is essential. In particular, a more detailed understanding of hydrological cycle response to transient climate change is required for successful adaptation and mitigation policies. In this study, we exploit large ensemble model experiments using the Community Earth System Model version 1.2.2 (CESM1) in which $\mathrm{CO}_{2}$ concentrations increase steadily and then decrease along the same path. Our results show that precipitation changes in the $\mathrm{CO}_{2}$ increasing and decreasing phases are nearly symmetrical over land but asymmetric over oceans. After $\mathrm{CO}_{2}$ concentrations peak, the ocean continues to uptake heat from the atmosphere, which is a key process leading the hydrological cycle's contrasting response over land and ocean. The symmetrical hydrological cycle response over land involves a complex interplay between rapid responses to $\mathrm{CO}_{2}$ and slower responses to ensuing warming. Therefore, the surface energy constraints lead to the contrasting hydrological response over land and ocean to $\mathrm{CO}_{2}$ forcing that needs to be verified and considered in climate change mitigation and adaption actions.

npj Climate and Atmospheric Science (2021)4:53; https://doi.org/10.1038/s41612-021-00206-6

\section{INTRODUCTION}

The global hydrological cycle's responses to rising temperatures driven by increasing greenhouse gas concentration significantly impact human activities and Earth's ecosystems ${ }^{1-8}$. Extreme rainfall events are becoming more intense $e^{9-11}$, raising serious concerns for human vulnerability ${ }^{12}$. Furthermore, damaging floods and drought frequency are projected to increase $\mathrm{e}^{13,14}$. The magnitude and rate of changes for regional hydrological events directly impact infrastructure, agriculture, and health ${ }^{15-17}$.

Previous studies examined precipitation changes in warmer climates by analyzing Coupled Model Intercomparison Projection Phase 5 (CMIP5) climate models. These climate change simulations are characterized by a wet-get-wetter/dry-get-drier pattern ${ }^{18-20}$ or a warmer-get-wetter pattern ${ }^{21,22}$ over the oceans. Water vapor content at typical lower troposphere temperatures is constrained to increase by no more than $7 \% \mathrm{~K}^{-1} 18$, which is the limit set by the Clausius-Clapeyron equation for saturation vapor pressure. Changes in the rate of global precipitation and evaporation response to warming differ significantly from water vapor content changes $^{2,3,18}$. Most CMIP5 models predict hydrological sensitivity around $1-3 \% \mathrm{~K}^{-117}$. The discrepancy between water vapor content changes and hydrological sensitivity can be explained by net radiative surface and atmospheric energy balance constraints that limit latent heat flux increases driven by a warmer climate $^{2}$, an important consequence of which is atmospheric circulation slowdown ${ }^{18,23}$. Although this perspective explains the hydrological cycle changes reasonably well, the scientific community requires more detailed understanding of hydrological cycle sensitivity to transient climate change ${ }^{24}$.

Studies investigating hydrological sensitivity to atmospheric $\mathrm{CO}_{2}$ removal are of importance, because they provide climate mitigation plans and emission reduction replacements ${ }^{25-29}$. Some climate mitigation studies assume a linear relationship between temperature and precipitation with respect to increasing or decreasing atmospheric $\mathrm{CO}_{2}$ concentrations ${ }^{30,31}$. The global hydrological cycle, however, demonstrates known hysteresis behavior and this has important implications for atmospheric emission reductions and carbon capture ${ }^{32}$. Furthermore, it is important to differentiate the hydrological cycle's response over oceans and land in a changing $\mathrm{CO}_{2}$ pathway. In this study, we focus on understanding the physical processes associated with hydrological sensitivities to idealized transient $\mathrm{CO}_{2}$ increases and removal over land and oceans, respectively, which has never been attempted in a previous study. We used 28 climate simulation ensemble sets along with a present-day climate simulation (PD simulation) using the standard Community Earth System Model version 1.2.2 (CESM1) (see "Methods").

A standard metric for assessing the sensitivity of climate to radiative forcing is the Equilibrium Climate Sensitivity, which quantifies the global average surface temperature change resulting from a doubling of $\mathrm{CO}_{2}$ concentration from a preindustrial period after the climate system equilibrates. However, in the present study we are interested in examining the physical processes determining hydrological sensitivity and how this determines global water cycle changes over time, thereby providing information relevant for ongoing climate mitigation and adaptation plans from the present climate condition.

Unless stated otherwise in the text, all analyses use the annual mean of the 28-member ensemble with the deviation obtained by subtracting the PD simulation climatology from the ensemble mean.

\section{RESULTS}

\section{Changes in precipitation and temperature to $\mathrm{CO}_{\mathbf{2}}$ forcing}

Figure 1a displays changes in $\mathrm{CO}_{2}$ concentration including an increase (ramp-up) and decrease (ramp-down) period. The $\mathrm{CO}_{2}$ concentration during the stabilization period is identical to that in

\footnotetext{
${ }^{1}$ Department of Marine Science and Convergent Engineering, Hanyang University, Ansan, South Korea. ${ }^{2}$ Department of Meteorology and National Centre for Earth Observation, University of Reading, Reading, UK. ${ }^{3}$ Department of Atmospheric Sciences/Irreversible Climate Change Research Center, Yonsei University, Seoul, South Korea.

凶email: swyeh@hanyang.ac.kr
} 


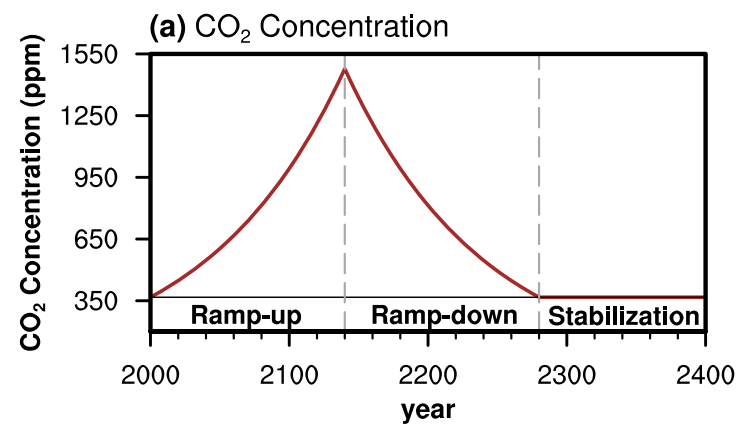

(c) Temperature

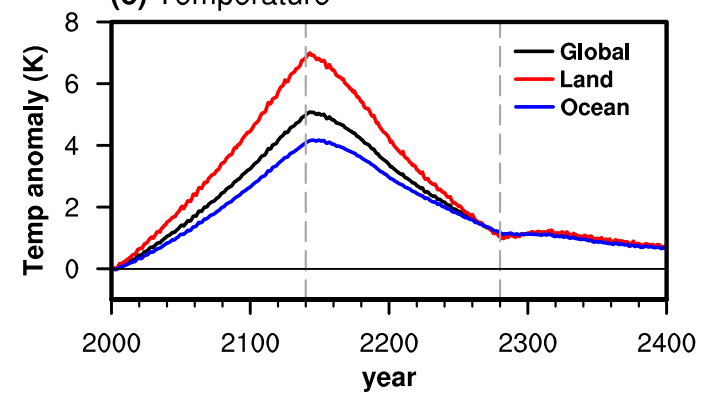

(b) Precipitation

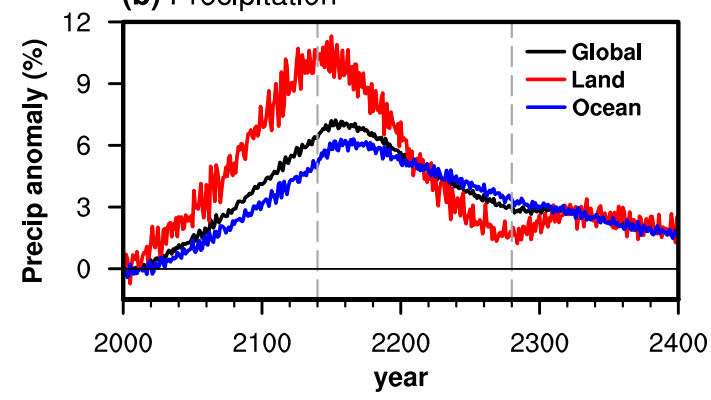

(d) Estimated Precipitation

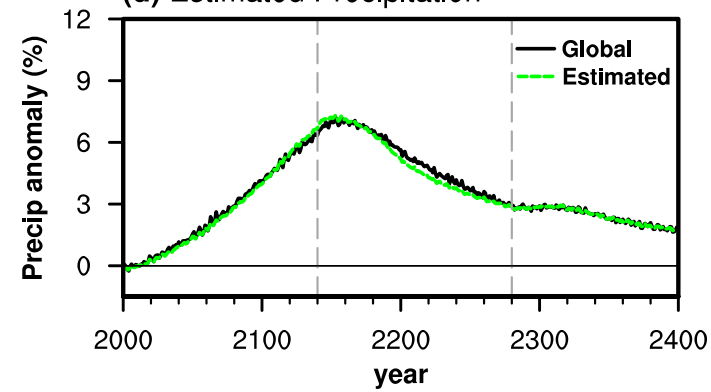

Fig. 1 Mean precipitation and temperature changes for a changing $\mathrm{CO}_{2}$ pathway. a Changes in $\mathrm{CO}_{2}$ concentration for an increase (rampup) period, a decrease (ramp-down) period, and a stabilization period. b Changes in global, land, and ocean mean precipitation from the ramp-up period to the stabilization period compared to the PD simulation. c Same as $\mathbf{b}$, except for surface temperature anomaly. $\mathbf{d}$ Changes in global mean precipitation from the ramp-up period to the stabilization period compared to the PD simulation (black) and the estimated global mean precipitation (green) using a simple conceptual model (see "Methods").

the PD simulation. Global mean precipitation increases during the $\mathrm{CO}_{2}$ ramp-up period and continues to increase for almost two decades after peak $\mathrm{CO}_{2}$ concentration (Fig. 1a, b).

Although the changes in global mean precipitation are almost identical to the changes in ocean precipitation, land precipitation changes are almost symmetric in a changing $\mathrm{CO}_{2}$ pathway (Fig. 1b). During the stabilization period, neither the global mean precipitation nor ocean and land precipitation returns to the present climate conditions, as the adjustment back to the PD simulation is likely to be slow after 280 continuous years of excess heating, much of which is stored in the deep ocean.

The precipitation is $2 \%$ higher than the present climate conditions after 120 years of stabilization in both land and ocean (Fig. 1b). This indicates that the precipitation responses to a changing $\mathrm{CO}_{2}$ pathway are not symmetric ${ }^{33,34}$. Similar behavior is seen for global mean surface temperature (Fig. 1c). The evolution of the temperature is largely corresponding to changes in $\mathrm{CO}_{2}$, suggesting a linear response, although its peak is delayed some years because of the heat capacity of the ocean, and the rate of temperature decrease in the ramp-down period is smaller in magnitude than the rate of increase in the ramp-up period ${ }^{27,35}$. We demonstrate that the hydrological cycle hysteresis is different for oceans and land (Fig. 1b). Ocean and land temperature changes in response to changing $\mathrm{CO}_{2}$ are similar, except for their magnitudes (Fig. 1C), which is mainly due to a large heat capacity in the ocean. Consequently, there is an almost linear relationship between precipitation and temperature change for land in response to a changing $\mathrm{CO}_{2}$ concentration (Supplementary Fig. 1 and see also Fig. 2b), which contrasts with the asymmetric relationship of precipitation and temperature change over the ocean (Supplementary Fig. 2 and see also Fig. 2c). We discuss the detailed physical processes later.

Global mean precipitation response to $\mathrm{CO}_{2}$ concentration changes is a combination of an initial fast (days to weeks) atmospheric adjustment to radiative forcing and a slower response to surface temperature change ${ }^{34}$. This has previously been explained by considering the atmospheric and surface energy budgets ${ }^{36}$, and it can be illustrated using a simple conceptual model (see "Methods" for details). It is found that the estimated global mean precipitation response based on the atmospheric and surface energy budgets is well matched with the global mean precipitation response simulated in CESM1 (Fig. 1d). This implies that the precipitation response $(\Delta P)$ is explained by the fast $\left(\Delta P_{\text {fast }}\right)$ and slow $\left(\Delta P_{\text {slow }}\right)$ precipitation response to temperature change in a CESM1. It is noteworthy that $\Delta$ indicates the deviation from PD simulation climatology. Therefore, we obtain the following equation

$\Delta P=\kappa \Delta T=\Delta P_{\text {fast }}+\Delta P_{\text {slow }}=\Delta P_{\text {fast }}+a \Delta T$

Here, $k$ is an apparent hydrological sensitivity, which represents the total change of precipitation per degree surface warming compared to PD climate. $a$ is a hydrological sensitivity, which is defined by the increase in precipitation solely due to a given change in temperature and it can be estimated from the stabilization phase where $\Delta P_{\text {fast }}=0$. This equation can be applied to global, ocean, or land, respectively.

An apparent global hydrological sensitivity $\left(\kappa_{\text {global }}\right)$ is $1.35 \% \mathrm{~K}^{-1}$ for the $\mathrm{CO}_{2}$ ramp-up period and it is significantly reduced to $1.09 \% \mathrm{~K}^{-1}$ for the $\mathrm{CO}_{2}$ ramp-down period (Supplementary Fig. 3a, b, d). However, $K_{\text {global }}$ increases to $2.54 \% \mathrm{~K}^{-1}$ during the stabilization period (Supplementary Fig. 3c, e and Table 1). This is consistent with energetic arguments in previous studies showing that global precipitation response to temperature change is larger when $\mathrm{CO}_{2}$ concentrations are constant than when they change over time ${ }^{34,37}$. It is noteworthy that the $\mathrm{CO}_{2}$ changes suppress the apparent global hydrological sensitivity below $2.54 \% \mathrm{~K}^{-1}$ equally in ramp-up and ramp-down. However, the delayed temperature response, which is mostly due to the ocean heat capacity, tends to suppress this response more in the ramp-down period (Fig. $2 a$ and Table 1). Therefore, removing 
(a) Global

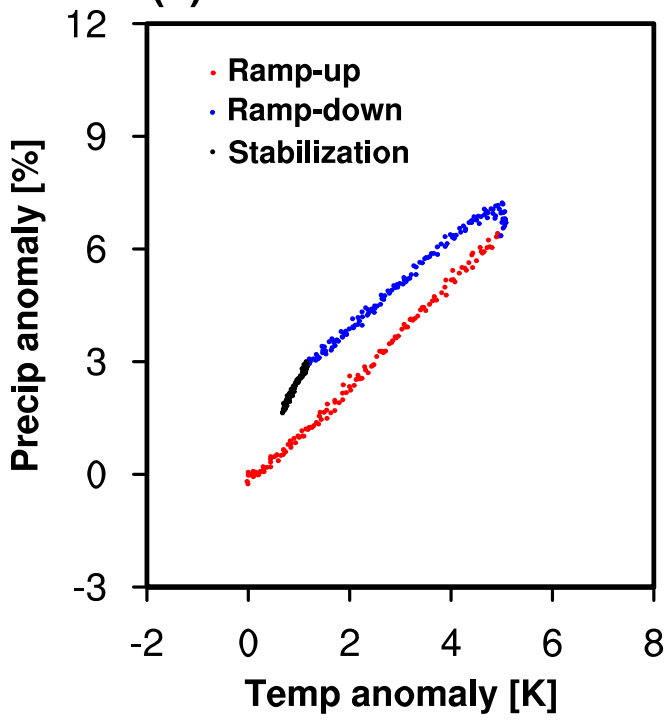

(c) Ocean

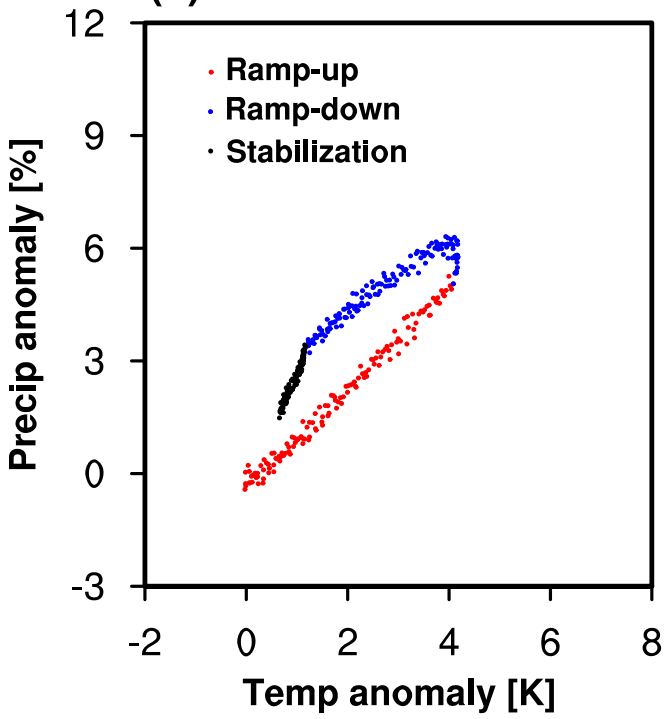

(b) Land



(d) Land minus Ocean

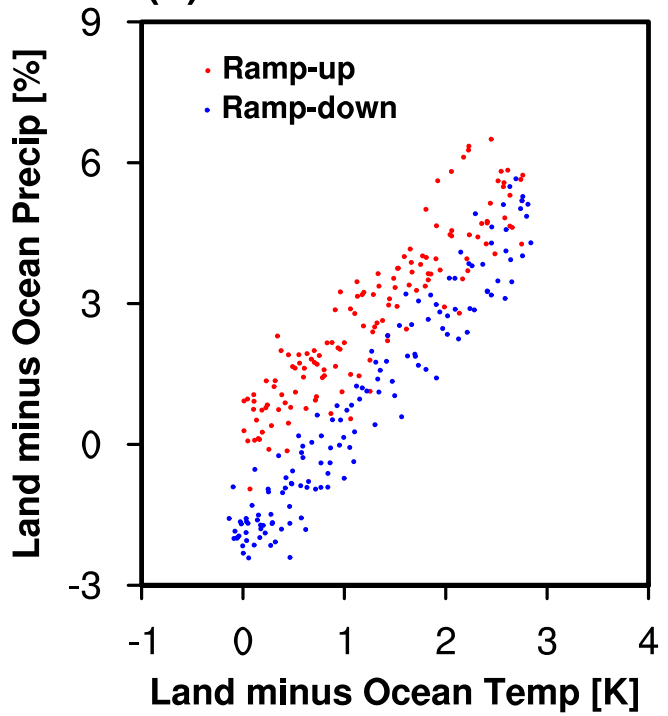

Fig. 2 Precipitation and temperature relationship changes during $\mathrm{CO}_{2}$ ramp-up, ramp-down, and stabilization periods. a The percentage change of global mean precipitation and the global mean surface temperature anomaly during $\mathrm{CO}_{2}$ ramp-up, ramp-down, and stabilization periods. b-d Same as a, except they are over land, ocean, and land minus ocean, respectively. Each dot represents the annual mean anomaly obtained by subtracting the PD simulation climatology from the ensemble mean. The percentage anomaly is defined as the difference between the ensemble mean and PD simulation divided by PD simulation.

Table 1. Summary of hydrological sensitivity and apparent hydrological sensitivity in a CESM1.

\begin{tabular}{lll}
\hline & $a$ Hydrological sensitivity & $\kappa$ Apparent hydrological sensitivity \\
\hline Global & $2.54 \% \mathrm{~K}^{-1}$ & $1.35 \% \mathrm{~K}^{-1}$ (ramp-up $\left.\uparrow\right)$ \\
& & $1.09 \% \mathrm{~K}^{-1}$ (ramp-down $\left.\downarrow\right)$ \\
Land & $1.21 \% \mathrm{~K}^{-1}$ & $1.57 \% \mathrm{~K}^{-1}$ (ramp-up $\left.\uparrow\right)$ \\
& & $1.61 \% \mathrm{~K}^{-1}$ (ramp-down $\left.\downarrow\right)$ \\
Ocean & $3.09 \% \mathrm{~K}^{-1}$ & $1.32 \% \mathrm{~K}^{-1}$ (ramp-up $\left.\uparrow\right)$ \\
& & $0.86 \% \mathrm{~K}^{-1}$ (ramp-down $\left.\downarrow\right)$ \\
\hline
\end{tabular}

atmospheric $\mathrm{CO}_{2}$ may cause a significant climate mitigation side effect by reducing the magnitude of precipitation to the ensuing cooling due to the mitigation and then abruptly increasing hydrological cycle sensitivity once the $\mathrm{CO}_{2}$ concentration stabilizes. This indicates a need for careful climate mitigation and emission reduction planning.

Contrasting hydrological sensitivity over land and ocean Subsequently, we calculate the precipitation response to atmospheric adjustment, to radiative forcing over oceans and land, 

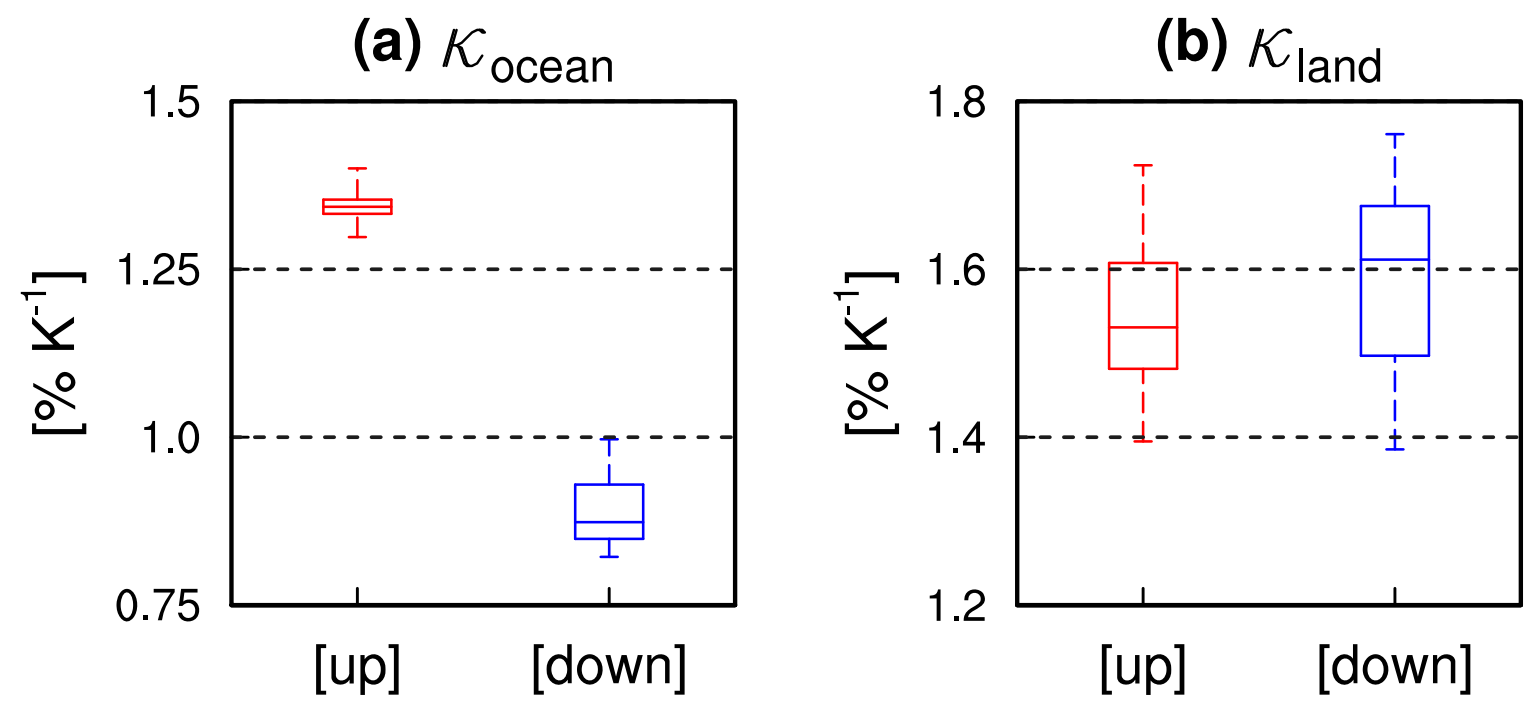

Fig. 3 Ocean and land hydrological sensitivity for each ensemble member. a Box-and-whisker diagram of apparent ocean hydrological sensitivity $\left(\kappa_{\text {ocean }}\right)$ during $\mathrm{CO}_{2}$ ramp-up and ramp-down periods. The box plot and whiskers represent quartiles with median and total range, respectively, in each period. $\mathbf{b}$ Same as $\mathbf{a}$, except apparent land hydrological sensitivity $\left(\kappa_{\text {land }}\right)$.

respectively, following Eq. (1).

$$
\begin{aligned}
& \Delta P_{\text {ocean fast } \uparrow}=\left(\kappa_{\text {ocean } \uparrow}-a_{\text {ocean }}\right) \Delta T_{\text {ocean }} \\
& \Delta P_{\text {ocean fast } \downarrow}=\left(\kappa_{\text {ocean } \downarrow}-a_{\text {ocean }}\right) \Delta T_{\text {ocean }} \\
& \Delta P_{\text {land fast }}=\left(\kappa_{\text {land }}-a_{\text {land }}\right) \Delta T_{\text {land }}, \\
& (\uparrow: \text { ramp }- \text { up period }, \downarrow: \text { ramp }- \text { down period })
\end{aligned}
$$

$a_{\text {ocean }}, a_{\text {land }}, \kappa_{\text {land }}, \kappa_{\text {ocean } \uparrow}$, and $\kappa_{\text {ocean } \downarrow}$ values are summarized with those in the globe in Table 1.

Here, the characteristics of the apparent hydrological sensitivity over the ocean $\left(\kappa_{\text {ocean }}\right)$ and land $\left(\kappa_{\text {land }}\right)$ are different during the ramp-up and ramp-down periods (Fig. 2b, $c$ and Table 1). Although $\kappa_{\text {ocean }}$ is not the same for the $\mathrm{CO}_{2}$ ramp-up $\left(\kappa_{\text {ocean } \uparrow}=\right.$ $\left.1.32 \% \mathrm{~K}^{-1}\right)$ and ramp-down $\left(\kappa_{\text {ocean } \downarrow}=0.86 \% \mathrm{~K}^{-1}\right.$ ) periods (Figs. $2 \mathrm{c}$ and $3 a), K_{\text {land }}\left(1.59 \% \mathrm{~K}^{-1}\right)$ is nearly identical over land for both periods (Figs. 2b and $3 \mathrm{~b}$ ) (see also "Methods"). This implies that $\mathrm{CO}_{2}$ changes equally influence the apparent hydrological sensitivity over land in ramp-up and ramp-down, which is in contrast to oceans.

On the other hand, land precipitation changes from rising temperatures, which are influenced by tropospheric temperature adjustments to $\mathrm{CO}_{2}$ radiative forcing, are increased by $0.38 \% \mathrm{~K}^{-1}$ $\left(\kappa_{\text {land }}\left(1.59 \% \mathrm{~K}^{-1}\right)-a_{\text {land }}\left(1.21 \% \mathrm{~K}^{-1}\right)\right)$. That is, the $\mathrm{CO}_{2}$ radiative forcing drives an additional increase in precipitation as land temperatures rise. This phenomenon could be related to land-ocean temperature contrast (Fig. 2d), i.e., warmer land than ocean may lead to more convergence over land, resulting in an additional increase in precipitation. In contrast, ocean precipitation changes from $\mathrm{CO}_{2}$ radiative forcing are suppressed by $1.77 \%$ $\mathrm{K}^{-1}$ during the $\mathrm{CO}_{2}$ ramp-up period $\left(\kappa_{\text {ocean } \uparrow}\left(1.32 \% \mathrm{~K}^{-1}\right)-a_{\text {ocean }}\right.$ $\left.\left(3.09 \% \mathrm{~K}^{-1}\right)\right)$ and $2.23 \% \mathrm{~K}^{-1}$ during the $\mathrm{CO}_{2}$ ramp-down period $\left(K_{\text {ocean } \downarrow}\left(0.86 \% \mathrm{~K}^{-1}\right)-a_{\text {ocean }}\left(3.09 \% \mathrm{~K}^{-1}\right)\right)$, implying that the $\mathrm{CO}_{2}$ radiative forcing drives an additional decrease in precipitation as ocean temperatures rise. These results indicate that $\mathrm{CO}_{2}$ radiative forcing leads to a contrast in the fast precipitation response between land and oceans ${ }^{38,39}$. Furthermore, the $\mathrm{CO}_{2}$ radiative forcing tends to suppress the precipitation changes over the ocean more in the ramp-down period than in the ramp-up period, which is due to the delayed ocean temperature response in the ramp-down period (Fig. 2d).

We used 28 climate simulation ensemble sets along with the PD simulation; therefore, a deviation in each ensemble from the

\begin{tabular}{lll|}
\hline $\begin{array}{l}\text { Table 2. Summary of SDs of apparent hydrological sensitivity }(\kappa) \text { in } 28 \\
\text { CESM1 ensemble members. }\end{array}$ \\
\hline & Ocean & Land \\
\hline Ramp-up $\uparrow$ & $0.023 \% \mathrm{~K}^{-1}$ & $0.080 \% \mathrm{~K}^{-1}$ \\
Ramp-down $\downarrow$ & $0.052 \% \mathrm{~K}^{-1}$ & $0.102 \% \mathrm{~K}^{-1}$ \\
\hline
\end{tabular}

ensemble mean could be due to internal climate variability ${ }^{40,41}$. We calculate the standard deviation (SD) of apparent ocean and land hydrological sensitivity in 28 climate simulation ensemble sets, respectively (Fig. 3 and see also Table 2). It is found that the SD of $\kappa_{\text {ocean } \downarrow}$ is significantly larger than that of $\kappa_{\text {ocean } \uparrow \text {, implying }}$ that the role of internal climate variability on apparent ocean hydrological sensitivity is large during the $\mathrm{CO}_{2}$ ramp-down period compared to that during the $\mathrm{CO}_{2}$ ramp-up period. A similar phenomenon is also observed in apparent hydrological sensitivity over land (Table 2). However, the increase of SD over land from the ramp-up to the ramp-down period is smaller than the ocean. These results indicate that the role of internal climate variability on apparent hydrological sensitivity over the ocean and land is changing from the $\mathrm{CO}_{2}$ ramp-up to the ramp-down period and its contribution differs over the ocean and land, respectively.

\section{Contrasting precipitation changes over land and ocean constrained by energy budget}

As precipitation changes are constrained by atmospheric and surface energy budgets $2,34,42,43$, we also examine the land and ocean global surface energy budgets.

$\Delta Q_{\mathrm{L}}=\Delta R_{\text {Lnet }}+\Delta R_{\text {Snet }}-\Delta Q_{\mathrm{S}}:$ Land

$\Delta Q_{\mathrm{L}}=\Delta R_{\text {Lnet }}+\Delta R_{\text {Snet }}-\Delta Q_{\mathrm{S}}+\Delta R_{\mathrm{TOA}}:$ Ocean

Here, $Q_{L}$ is latent heat flux from the surface, $R_{\mathrm{Lnet}}$ is net longwave radiation, $R_{\text {Snet }}$ is net shortwave radiation, and $Q_{S}$ is the upward sensible heat flux. $R_{\mathrm{TOA}}$ is the net radiation at the top of the atmosphere, which balances with ocean heat uptake (i.e., $\left.-R_{\text {TOA }}\right)^{37}$ and we assume land heat uptake is negligible. The righthand side of Eq. (5) can be seen in Fig. 4a. Changes in net longwave radiation $\left(\Delta R_{\text {Lnet }}\right)$ and net shortwave radiation $\left(\Delta R_{\text {Snet }}\right)$ are compensated by changes in sensible heat flux $\left(\Delta Q_{S}\right)$. 
Land

(a) Longwave, Shortwave, Sensible

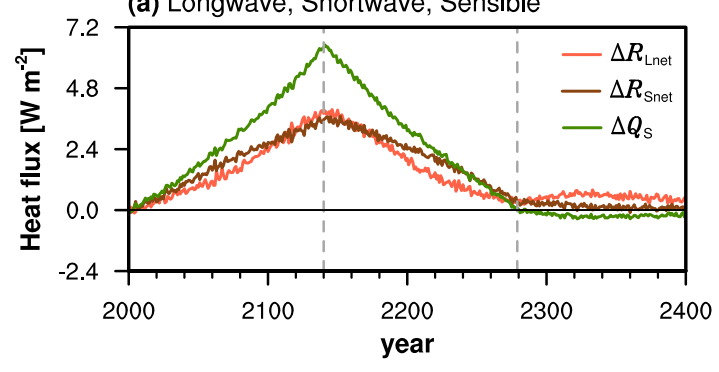

(b) Latent, Radiative cooling



(c) Latent \& Precipitation

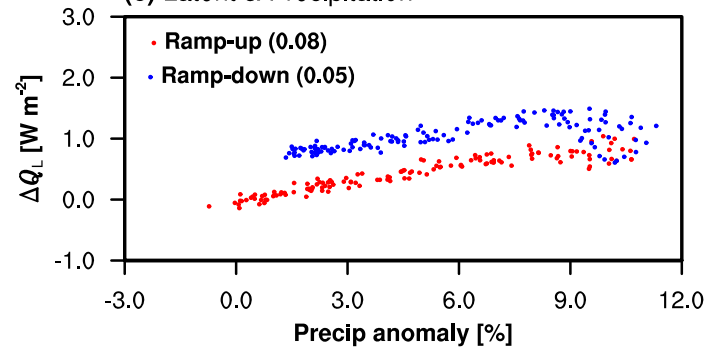

Ocean

(d) Longwave, Shortwave, Sensible

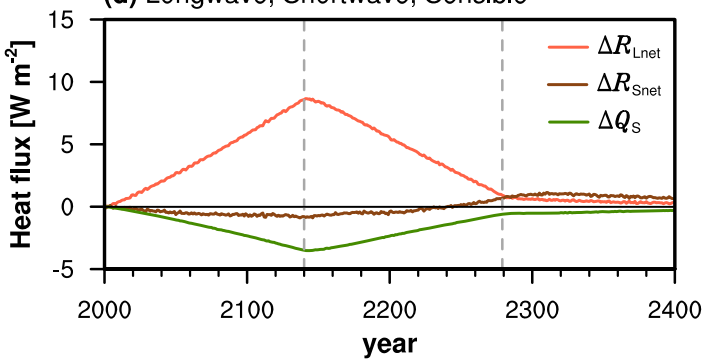

(e) Latent, Ocean heat uptake, Radiative cooling

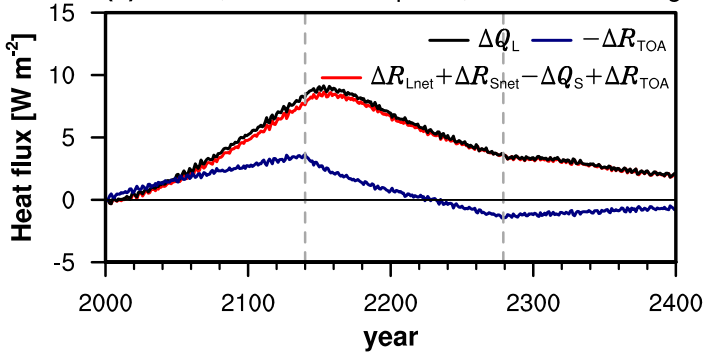

(f) Latent \& Precipitation



Fig. 4 Changes in land and ocean surface energy budgets and precipitation changes. Changes in land a $\Delta R_{\mathrm{Lnet}}, \Delta R_{\text {Snet, }}$ and $\Delta Q_{\mathrm{S}}, \mathbf{b} \Delta Q_{\mathrm{L}}$ and $\left(\Delta R_{\text {Lnet }}+\Delta R_{\text {Snet }}-\Delta Q_{\mathrm{S}}\right)$ during $\mathrm{CO}_{2}$ ramp-up, ramp-down, and stabilization periods. c Relationship between $\Delta Q_{\mathrm{L}}$ and precipitation percentage change in land during $\mathrm{CO}_{2}$ ramp-up and ramp-down periods. Changes in ocean d $\Delta R_{\mathrm{Lnet}}, \Delta R_{\text {Snet, }}$ and $\Delta Q_{\mathrm{S}}$, e $\Delta Q_{\mathrm{L}}\left(\Delta R_{\mathrm{Lnet}}+\Delta R_{\mathrm{Snet}}-\Delta Q_{\mathrm{S}}+\right.$ $\left.\Delta R_{\mathrm{TOA}}\right)$ and $-\Delta R_{\mathrm{TOA}}$ during $\mathrm{CO}_{2}$ ramp-up, ramp-down, and stabilization periods. $\mathrm{f}$ Relationship between $\Delta Q_{\mathrm{L}}$ and precipitation percentage change in ocean during $\mathrm{CO}_{2}$ ramp-up and ramp-down periods. $\Delta$ indicates the deviation from the PD climatology simulation. Bracket values represent linear regression coefficients between $\Delta Q_{\mathrm{L}}$ and the precipitation percentage change, which are statistically significant at a $99 \%$ confidence level.

Consequently, changes in latent heat flux $\left(\Delta Q_{L}\right)$ balance with $\Delta R_{\text {Lnet }}, \Delta R_{\text {Snet, }}$ and $\Delta Q_{\mathrm{S}}$ (Fig. 4b). As $\Delta Q_{\mathrm{L}}$ changes are tied to land precipitation changes (Fig. 4c), we conclude that the almost symmetric land precipitation response (see also Supplementary Fig. 1) is mainly constrained by the symmetric change in surface energy terms $\Delta R_{\text {Lnet }} \Delta R_{\text {Snet, }}$ and $\Delta Q_{\mathrm{S}}$ (Fig. 4a). This implies that the overall land precipitation response is strongly constrained by the fast response to $\mathrm{CO}_{2}$ radiative forcing's tropospheric temperature adjustment. Over land, the tropospheric temperature adjustments during $\mathrm{CO}_{2}$ ramp-up and ramp-down decreases atmospheric stability and increases convection compared to that during the present climate condition $2,36,44$, leading to increased precipitation ${ }^{45}$. This is also explained by an increased land-ocean temperature contrast with warming (see also Fig. 2d), which drives decreased atmospheric stability and dominates over the direct atmospheric and surface heating effect of elevated $\mathrm{CO}_{2}$ over land. The land-ocean warming contrast relating to differing thermal capacities of land and ocean but also contrasting surface feedbacks explains the increased hydrological sensitivity over land $^{46}$ (i.e., $0.38 \% \mathrm{~K}^{-1}$ ).

Figure $4 \mathrm{~d}$, e display the right-hand side of Eq. (6) $\left(\Delta R_{\text {Lnet }}, \Delta R_{\text {Snet, }}\right.$ $\Delta Q_{\mathrm{S}}$, and $\left.\Delta R_{\mathrm{TOA}}\right)$ for oceans, respectively. Figure $4 \mathrm{e}$ also shows $\Delta \mathrm{Q}_{\mathrm{L}}$ changes are identical to the four surface energy terms combined and it is also tied to ocean precipitation changes (Fig. 4f). Therefore, the ocean precipitation response is also constrained by changes in surface energy terms $\Delta R_{\text {Lnet, }} \Delta R_{\text {Snet }} \Delta Q_{\mathrm{S}}$, and $\Delta R_{\mathrm{TOA}}$, consistent with land (Fig. $4 \mathrm{~b}, \mathrm{e})$. In contrast to land, however, changes in sensible heat flux $\left(\Delta Q_{S}\right)$ are negative (i.e., downward) over the ocean during both $\mathrm{CO}_{2}$ ramp-up and ramp-down periods (Fig. 4d). This is because land warms more than ocean; therefore, the sea surface temperature is changing less than the atmosphere above it (Supplementary Fig. 4). This is also associated with the suppression of ( $\left.\kappa_{\text {ocean }}-a_{\text {ocean }}\right)$ during both periods (Eqs. (2) and (3)), which is explained by the direct atmospheric heating by $\mathrm{CO}_{2}$ radiative forcing, while the land-ocean warming contrast partly offset this effect.

In addition, changes in both ocean heat uptake (- $\left.\Delta R_{\mathrm{TOA}}\right)$ (Fig. 4e) and net shortwave radiation $\left(\Delta R_{\text {snet }}\right)$ (Fig. $\left.4 \mathrm{~d}\right)$ explain the asymmetric precipitation response to oceanic temperature changes (Fig. 4f). Unlike the symmetric $\Delta Q_{\mathrm{S}}$ and $\Delta R_{\text {Lnet }}$ changes, both $\Delta R_{\text {Snet }}$ and $\Delta R_{\mathrm{TOA}}$ changes are asymmetric. $\Delta R_{\text {Snet }}$ changes its sign in the latter stages of the $\mathrm{CO}_{2}$ ramp-down period and the ocean receives more net shortwave radiation during the $\mathrm{CO}_{2}$ stabilization period (Fig. 4d). After peak atmospheric $\mathrm{CO}_{2}$ 
concentration, on the other hand, $-\Delta R_{\mathrm{TOA}}$ slowly decreases and changes sign in the middle of the $\mathrm{CO}_{2}$ ramp-down period (Fig. 4e). These characteristics contribute to the asymmetric precipitation response over the oceans. In particular, the oceans absorb heat until the middle of the $\mathrm{CO}_{2}$ ramp-down period despite the $\mathrm{CO}_{2}$ concentration decrease. In addition, the oceans continue to release heat despite a fixed $\mathrm{CO}_{2}$ concentration during the stabilization period. We speculate that this may contribute to increased $\Delta R_{\text {Snet }}$ during and after the latter stages of the $\mathrm{CO}_{2}$ ramp-down (Fig. 4d). There is a possibility that ocean heat release into atmosphere may reduce the amount of low-level clouds over the oceans during the stabilization period (Supplementary Fig. 5) through enhanced low-level turbulence in boundary layer ${ }^{47}$. This may act to increase net shortwave radiation at the surface. However, we cannot exclude the possibility that the extra heat released to the atmosphere may destabilize it, enhance convection, leading to more cloudiness, and hence reduced shortwave radiation at the surface. It is therefore valuable to further analyze the detailed mechanisms, although it is beyond the scope of the present study.

Meanwhile, there is a contrast in both "slopes" and "direction" in the relationship between $\Delta \mathrm{Q}_{\mathrm{L}}$ and precipitation percentage change over land and the ocean during $\mathrm{CO}_{2}$ ramp-up and ramp-down periods, respectively (Fig. $4 \mathrm{c}$, f). This implies that there is different moisture divergence from over the ocean and convergence over land during $\mathrm{CO}_{2}$ ramp-up and ramp-down periods. The low slopes over land (Fig. 4c) reflects weaker dependence of precipitation on evaporation than that over the ocean. Therefore, the enhanced precipitation must be due more to enhanced moisture convergence from the oceans (e.g., stronger monsoons) than to local evaporation. However, the increased latent heat loss through surface evaporation over land during the $\mathrm{CO}_{2}$ ramp-down period (Fig. 4c) does not reflect warmer or wetter land during this period, because temperature is relatively symmetric between the $\mathrm{CO}_{2}$ ramp-up and ramp-down periods (see Fig. 1b). Therefore, the increased latent heat loss over land could be explained by a smaller contribution of moisture import from the oceans to land precipitation during the $\mathrm{CO}_{2}$ ramp-down period. A smaller contribution of moisture convergence to precipitation over land during the $\mathrm{CO}_{2}$ ramp-down period then requires more surface evaporation over land for the same precipitation anomaly. On the other hand, the larger slopes in the relationship between $\Delta Q_{\mathrm{L}}$ and precipitation percentage change over the ocean than land (Fig. 4c, f) indicates that precipitation over the ocean must be closely proportional to surface evaporation compared to that over land. Figure $4 \mathrm{f}$ also indicates that less surface evaporation over the ocean is required during the $\mathrm{CO}_{2}$ ramp-down period for the same precipitation anomaly compared with the $\mathrm{CO}_{2}$ ramp-up period, because there is less moisture export to land during the $\mathrm{CO}_{2}$ ramp-down period.

\section{DISCUSSION}

The climate system response to changes in the Earth's radiative balance depends on the timescale ${ }^{48}$. The transient climate response, which is formally defined as the global mean surface warming at the time of doubling of $\mathrm{CO}_{2}$ in an idealized $1 \%$ year ${ }^{-1}$ $\mathrm{CO}_{2}$ increase experiment, quantifies warming in response to a changing forcing prior to the deep ocean being in equilibrium with the forcing. On the other hand, the equilibrium climate sensitivity is defined as the warming for doubling $\mathrm{CO}_{2}$ in the atmosphere relative to pre-industrial climate, after the climate reached its new equilibrium ${ }^{49}$. To project correctly Earth's future climate, therefore, it is fundamental to understand the transient climate response and equilibrium climate sensitivity ${ }^{50-52}$. In particular, the understanding of the hydrological cycle response to transient climate change is essential for successful adaptation and mitigation policies.
Although the response of the global hydrological cycle has been qualitatively examined by analyzing an atmospheric general circulation model and state-of-the-art climate models, there is little study to examine the contrast of hydrological cycle over land and ocean in a changing $\mathrm{CO}_{2}$ pathway with large ensemble simulations.

We found that there is an almost linear relationship between precipitation and temperature change for land in response to a changing $\mathrm{CO}_{2}$ concentration, which contrasts with the asymmetric relationship of precipitation and temperature change over the ocean. Our results indicate that ocean heat uptake and land-ocean warming contrast is the key to the contrasting precipitation responses between land and oceans. The oceans absorb heat until the middle of the $\mathrm{CO}_{2}$ ramp-down period and it continues to release heat despite a fixed $\mathrm{CO}_{2}$ concentration during the stabilization period, resulting in an asymmetric relationship of precipitation and temperature changes constrained by surface energy budget. In particular, the $\mathrm{CO}_{2}$ radiative forcing drives an additional increase in precipitation as land temperatures rise, which could be related to land-ocean temperature contrast. In contrast, ocean precipitation changes from $\mathrm{CO}_{2}$ radiative forcing are suppressed during the ramp-down period. This result implies that changing $\mathrm{CO}_{2}$ pathway mitigation and adaptive actions should incorporate the contrasting hydrological cycle responses of the land and ocean, and underlines the importance of confirming simulated responses in the hydrological cycle to $\mathrm{CO}_{2}$ across all timescale from days to decades. In addition, it would be necessary to examine the hydrological cycle to $\mathrm{CO}_{2}$ radiative forcing over the tropical vs. the extratropical to understand its regional characteristics.

All analyses used the annual mean of the 28-member ensemble in the present study; however, it would be valuable to understand how the seasonality of precipitation to $\mathrm{CO}_{2}$ forcing changes over land and the ocean. Transient climate changes and slow adjustment processes during the stabilization period were not found to substantially affect the seasonality of precipitation over both land and ocean, only the magnitude (Supplementary Fig. 6).

Although the ramp-up and ramp-down periods are symmetric in terms of $\mathrm{CO}_{2}$ concentrations, they are not symmetric at all in terms of forcing relative to the PD climate, as extra heating relative to the PD climate is occurring during both ramp-up and rampdown periods. The climate system at the beginning of the stabilization period has already absorbed the integrated effects of extra heating during both ramp-up and ramp-down periods. Therefore, the stabilization period is unlike the PD climate in terms of heat content and distribution in the ocean in spite of the same $\mathrm{CO}_{2}$ concentration. This hysteresis of the global hydrological cycle is expected to be less apparent if assessing in the context of a symmetrical ramp-up and ramp-down in radiative forcing. In that case, there would be no net heat loss or gain after the 280 years relative to the PD climate in which any hysteresis could be weak. Although the present study focuses on the climate transition from $\mathrm{CO}_{2}$ ramp-up to ramp-down, it would be also necessary to understand the slow adjustment process during the stabilization period.

\section{METHODS}

\section{CESM1 experiments}

To investigate the hydrological cycles' contrasting response over land and ocean to $\mathrm{CO}_{2}$ emission ramp-up and ramp-down, we conducted experimental climate model simulations. The model used in this study is a fully coupled CESM1, which has the same component models and coupling of the CESM1 with the Community Atmosphere Model version 5 in CMIP5. CESM1 is the Community Atmosphere Model version 5 coupled to the Parallel Ocean Program version 2, the Community Land Model version 4 , and the Los Alamos Sea Ice Model, all at $\sim 1^{\circ}$ horizontal 
resolution ${ }^{53}$. Vertical resolutions were 30 and 60 levels for the atmosphere and ocean, respectively. The land carbon cycle was also included ${ }^{54}$.

We performed two kinds of simulations. One is a PD simulation with a constant $\mathrm{CO}_{2}$ concentration ( $1 \times \mathrm{CO}_{2}, 367$ p.p.m.) of over 900 years, where we extracted 28 initial conditions from the PD simulation. The 28 initial ocean condition was taken from the PD simulation arbitrarily. Also, a $\mathrm{CO}_{2}$ ramp-up and -down experiment was performed in each 28 ensemble member. This experiment employed an increasing atmospheric $\mathrm{CO}_{2}$ concentration at a rate of $1 \%$ year ${ }^{-1}$ until $\mathrm{CO}_{2}$ quadrupling $\left(4 \times \mathrm{CO}_{2}\right.$, 1478 p.p.m., $\mathrm{CO}_{2}$ ramp-up simulation) and then a decreasing $\mathrm{CO}_{2}$ forcing to the same rate over 140 years until reaching the original value $\left(1 \times \mathrm{CO}_{2}\right.$, 367 p.p.m., $\mathrm{CO}_{2}$ ramp-down simulation). In addition, we integrated a restoring run of 120 years with a constant $\mathrm{CO}_{2}$ concentration $\left(1 \times \mathrm{CO}_{2}\right.$, 367 p.p.m., $\mathrm{CO}_{2}$ stabilization simulation).

\section{Simple model for global precipitation response}

Global mean precipitation response $(\Delta P)$ is balanced by the fast component $(f \Delta F)$ in which the atmosphere rapidly adjusts to changes in top of atmosphere radiative forcing, $\Delta F$, and a slow component $\left(a_{\text {global }} \Delta T\right)$ which quantifies the global mean precipitation response to the global mean surface temperature change, $\Delta T$, as follows ${ }^{2}$ :

$\Delta P \sim-f \Delta F+a_{\text {global }} \Delta T$

where $f$ is the fraction of radiative forcing manifest in the atmosphere and $a_{\text {global }}$ is the global hydrological sensitivity that quantifies the global mean precipitation response to the global mean temperature warming alone. It is noteworthy that $a_{\text {global }}$ is obtained from the stabilization period in CESM1 experiment (Fig. 2a and Supplementary Fig. $3 c, e), 2.54 \% \mathrm{~K}^{-1} . f$ is 0.8 for the fraction of the $\mathrm{CO}_{2}$ forcing that heats the atmosphere ${ }^{36}$. In addition, the $\Delta F$ can be simplified as $5.35 \mathrm{ln}$ $\left(\mathrm{CO}_{2} / 367 \text { p.p.m. }\right)^{55}$ and $\Delta T$ is the model simulated surface temperature response in a CESM. Based on this simple model, we are able to calculate the estimated global mean precipitation response to a $\mathrm{CO}_{2}$ radiative forcing and compare with the results in CESM1 experiment (Fig. 1d).

\section{Apparent hydrologic sensitivity over land}

We define the proportionality constant, $k$ (i.e., the apparent hydrological sensitivity), as both the fast and slow precipitation response in the ocean and land during the $\mathrm{CO}_{2}$ ramp-up and ramp-down periods, respectively. However, land's hydrological sensitivity is nearly identical during the rampup $(\uparrow)$ period $\left(1.57 \% \mathrm{~K}^{-1}\right)$ and ramp-down $(\downarrow)$ period $\left(1.61 \% \mathrm{~K}^{-1}\right.$ ) (see Fig. $3 \mathrm{~b})$, indicating the following relationship:

$\Delta P_{\text {land }}=k_{\text {land }} \Delta T_{\text {land }}(\operatorname{ramp}-\operatorname{up}(\uparrow)$ and ramp - down $(\downarrow)$ periods $)$

Here, $\kappa_{\text {land }}=\left(\kappa_{\text {land } \uparrow}+\kappa_{\text {land } \downarrow}\right) / 2$, i.e., $1.59 \% \mathrm{~K}^{-1}$.

\section{DATA AVAILABILITY}

Data for the CESM simulations used in the current study are available on request from the authors (sysong619@gmail.com or js-shin@yonsei.ac.kr).

\section{CODE AVAILABILITY}

All the codes used to generate the results of this study are available on request from the authors (sysong619@gmail.com or js-shin@yonsei.ac.kr).

Received: 12 April 2021; Accepted: 28 September 2021; Published online: 27 October 2021

\section{REFERENCES}

1. Allan, R. P. \& Soden, B. J. Atmospheric warming and the amplification of precipitation extremes. Science 321, 1481-1484 (2008).

2. Allen, M. R. \& Ingram, W. J. Constraints on future changes in climate and the hydrologic cycle. Nature 419, 228-232 (2002).

3. Cubasch, U. \& Meehl, G. In Climate Change 2001: The Scientific Basis (eds. Houghton, J. T. et al.) 525-582 (Cambridge Univ. Press, 2001).

4. Haug, G. H. et al. Climate and the collapse of Maya civilization. Science 299, 1731-1735 (2003).
5. Lemordant, L., Gentine, P., Swann, A. S., Cook, B. I. \& Scheff, J. Critical impact of vegetation physiology on the continental hydrologic cycle in response to increasing CO2. Proc. Natl Acad. Sci. USA 115, 4093-4098 (2018).

6. Lesk, C., Rowhani, P. \& Ramankutty, N. Influence of extreme weather disasters on global crop production. Nature 529, 84-87 (2016).

7. Ma, J. et al. Hydrological cycle changes under global warming and their effects on multiscale climate variability. Ann. NY Acad. Sci. 1472, 21-48 (2020).

8. Roderick, M., Sun, F., Lim, W. H. \& Farquhar, G. A general framework for understanding the response of the water cycle to global warming over land and ocean. Hydrol. Earth Syst. Sci. 18, 1575-1589 (2014).

9. Schiermeier, Q. Increased flood risk linked to global warming. Nature 470, 316 (2011).

10. Coumou, D. \& Rahmstorf, S. A decade of weather extremes. Nat. Clim. Change 2, 491-496 (2012).

11. Diffenbaugh, N. S. et al. Quantifying the influence of global warming on unprecedented extreme climate events. Proc. Natl Acad. Sci. USA 114, 4881-4886 (2017).

12. Peterson, T. C., Stott, P. A. \& Herring, S. Explaining extreme events of 2011 from a climate perspective. Bull. Am. Meteorol. Soc. 93, 1041-1067 (2012).

13. Arnell, N. W., Lowe, J. A., Challinor, A. J. \& Osborn, T. J. Global and regional impacts of climate change at different levels of global temperature increase. Clim. Change 155, 377-391 (2019).

14. Arnell, N. W. et al. The global and regional impacts of climate change under representative concentration pathway forcings and shared socioeconomic pathway socioeconomic scenarios. Environ. Res. Lett. 14, 084046 (2019).

15. Watts, N. et al. Health and climate change: policy responses to protect public health. Lancet 386, 1861-1914 (2015).

16. Kundzewicz, Z. W. et al. Flood risk and climate change: global and regional perspectives. Hydrol. Sci. J. 59, 1-28 (2014).

17. Collins, M. et al. In Climate Change 2013: The Physical Science Basis (eds. Stocker, T. F. et al.) 1029-1136 (Cambridge Univ. Press, 2013).

18. Held, I. M. \& Soden, B. J. Robust responses of the hydrological cycle to global warming. J. Clim. 19, 5686-5699 (2006).

19. Chou, C., Neelin, J. D., Tu, J.-Y. \& Chen, C.-T. Regional tropical precipitation change mechanisms in ECHAM4/OPYC3 under global warming. J. Clim. 19, 4207-4223 (2006).

20. Chou, C., Neelin, J. D., Chen, C.-A. \& Tu, J.-Y. Evaluating the "rich-get-richer" mechanism in tropical precipitation change under global warming. J. Clim. 22, 1982-2005 (2009).

21. Xie, S.-P. et al. Global warming pattern formation: sea surface temperature and rainfall. J. Clim. 23, 966-986 (2010).

22. Huang, P., Xie, S.-P., Hu, K., Huang, G. \& Huang, R. Patterns of the seasonal response of tropical rainfall to global warming. Nat. Geosci. 6, 357-361 (2013).

23. Chou, C. \& Chen, C.-A. Depth of convection and the weakening of tropical circulation in global warming. J. Clim. 23, 3019-3030 (2010).

24. Allan, R. P. et al. Advances in understanding large-scale responses of the water cycle to climate change. Ann. NY Acad. Sci. 1472, 49-75 (2020).

25. Wu, P., Ridley, J., Pardaens, A., Levine, R. \& Lowe, J. The reversibility of $\mathrm{CO}_{2}$ induced climate change. Clim. Dyn. 45, 745-754 (2015).

26. Cao, L., Bala, G. \& Caldeira, K. Why is there a short-term increase in global precipitation in response to diminished $\mathrm{CO}_{2}$ forcing? Geophys. Res. Lett. 38, https:// doi.org/10.1029/2011GL046713 (2011).

27. Boucher, O. et al. Reversibility in an Earth System model in response to $\mathrm{CO} 2$ concentration changes. Environ. Res. Lett. 7, 024013 (2012).

28. Keller, D. P., Feng, E. Y. \& Oschlies, A. Potential climate engineering effectiveness and side effects during a high carbon dioxide-emission scenario. Nat. Commun. 5, 3304 (2014).

29. Ricke, K. L. \& Caldeira, K. Maximum warming occurs about one decade after a carbon dioxide emission. Environ. Res. Lett. 9, 124002 (2014).

30. Mitchell, T. D. Pattern scaling: an examination of the accuracy of the technique for describing future climates. Clim. Change 60, 217-242 (2003).

31. Wilby, R. L. et al. A review of climate risk information for adaptation and development planning. Int. J. Clim. 29, 1193-1215 (2009).

32. McNutt, M. K. et al. Climate Intervention: Carbon Dioxide Removal and Reliable Sequestration (National Research Council of the National Academies, 2015).

33. Chadwick, R., Wu, P., Good, P. \& Andrews, T. Asymmetries in tropical rainfall and circulation patterns in idealised $\mathrm{CO} 2$ removal experiments. Clim. Dyn. 40, 295-316 (2013).

34. Andrews, T. \& Forster, P. M. The transient response of global-mean precipitation to increasing carbon dioxide levels. Environ. Res. Lett. 5, 025212 (2010).

35. Samanta, A. et al. Physical climate response to a reduction of anthropogenic climate forcing. Earth Interact. 14, 1-11 (2010).

36. Andrews, T., Forster, P. M., Boucher, O., Bellouin, N. \& Jones, A. Precipitation, radiative forcing and global temperature change. Geophys. Res. Lett. 37, L14701 (2010) 
37. Wu, P., Wood, R., Ridley, J. \& Lowe, J. Temporary acceleration of the hydrological cycle in response to a CO2 rampdown. Geophys. Res. Lett. 37, L12705 (2010).

38. Samset, B. H. et al. Weak hydrological sensitivity to temperature change over land, independent of climate forcing. npj Clim. Atmos. Sci. 1, 1-8 (2018).

39. Richardson, T. et al. Drivers of precipitation change: an energetic understanding. J. Clim. 31, 9641-9657 (2018).

40. Tebaldi, C. \& Knutti, R. The use of the multi-model ensemble in probabilistic climate projections. Philos. Tran. R. Soc. 365, 2053-2075 (2007).

41. Deser, C., Phillips, A., Bourdette, V. \& Teng, H. Uncertainty in climate change projections: the role of internal variability. Clim. Dyn. 38, 527-546 (2012).

42. Allan, R. P. et al. Physically consistent responses of the global atmospheric hydrological cycle in models and observations. Surv. Geophys. 35, 533-552 (2014).

43. Boer, G. Climate change and the regulation of the surface moisture and energy budgets. Clim. Dyn. 8, 225-239 (1993).

44. Lambert, F. H. \& Webb, M. J. Dependency of global mean precipitation on surface temperature. Geophys. Res. Lett. 35, L16706 (2008).

45. Berg, P., Moseley, C. \& Haerter, J. O. Strong increase in convective precipitation in response to higher temperatures. Nat. Geosci. 6, 181-185 (2013).

46. Byrne, M. P. \& O'Gorman, P. A. The response of precipitation minus evapotranspiration to climate warming: Why the "wet-get-wetter, dry-get-drier" scaling does not hold over land. J. Clim. 28, 8078-8092 (2015).

47. Nuijens, L. \& Siebesma, A. P. Boundary layer clouds and convection over subtropical oceans in our current and in a warmer climate. Curr. Clim. Change Rep. 5, 80-94 (2019).

48. Knutti, R., Rugenstein, M. A. \& Hegerl, G. C. Beyond equilibrium climate sensitivity. Nat. Geosci. 10, 727-736 (2017).

49. Randall, D. A. et al. In Climate Change 2007: The Physical Science Basis (eds. Solomon, S. et al.) 589-662 (Cambridge Univ. Press, 2007).

50. Knutti, R., Stocker, T. F., Joos, F. \& Plattner, G.-K. Constraints on radiative forcing and future climate change from observations and climate model ensembles. Nature 416, 719-723 (2002).

51. Hegerl, G. C. et al. In Climate Change 2007: The Physical Science Basis (eds. Solomon, S. et al.) 663-746 (Cambridge Univ. Press, 2007).

52. Meehl, G. A. et al. In Climate Change 2007: The Physical Science Basis (eds. Solomon, S. et al.) 747-845 (Cambridge Univ. Press, 2007).

53. Hurrell, J. W. et al. The community earth system model: a framework for collaborative research. Bull. Am. Meteorol. Soc. 94, 1339-1360 (2013).

54. Lawrence, D. M. et al. Parameterization improvements and functional and structural advances in version 4 of the Community Land Model. J. Adv. Model. Earth Syst. 3, M03001 (2011).

55. Myhre, G., Highwood, E. J., Shine, K. P. \& Stordal, F. New estimates of radiative forcing due to well mixed greenhouse gases. Geophys. Res. Lett. 25, 2715-2718 (1998).

\section{ACKNOWLEDGEMENTS}

This work was supported by National Research Foundation Grant NRF2018R1A5A1024958.

\section{AUTHOR CONTRIBUTIONS}

S.W.Y. conceived of the study. S.Y.S. and J.S.S. conducted analysis and model experiments. S.W.Y. and R.P.A. wrote the manuscript with comments and input from S.I.A.

\section{COMPETING INTERESTS}

The authors declare no competing interests

\section{ADDITIONAL INFORMATION}

Supplementary information The online version contains supplementary material available at https://doi.org/10.1038/s41612-021-00206-6.

Correspondence and requests for materials should be addressed to Sang-Wook Yeh.

Reprints and permission information is available at http://www.nature.com/ reprints

Publisher's note Springer Nature remains neutral with regard to jurisdictional claims in published maps and institutional affiliations.

cc) (i)

Open Access This article is licensed under a Creative Commons Attribution 4.0 International License, which permits use, sharing, adaptation, distribution and reproduction in any medium or format, as long as you give appropriate credit to the original author(s) and the source, provide a link to the Creative Commons license, and indicate if changes were made. The images or other third party material in this article are included in the article's Creative Commons license, unless indicated otherwise in a credit line to the material. If material is not included in the article's Creative Commons license and your intended use is not permitted by statutory regulation or exceeds the permitted use, you will need to obtain permission directly from the copyright holder. To view a copy of this license, visit http://creativecommons. org/licenses/by/4.0/.

(c) The Author(s) 2021 